\title{
Contraceptive Uptake Among Postpartum Mothers 15-49 Years of Age in Kalisizo Hospital, Kyotera District, Central Uganda
}

\author{
Kizito Omona $[\mathrm{PhD}]^{1}{ }^{*}$; Emmanuel Ssekyeru ${ }^{1}$; Peter Kirya ${ }^{1}$; Julius Mutebi ${ }^{1}$; Isaac Tenywa ${ }^{1}$; \\ Alex Mugabi ${ }^{1}$; Benard Ochieng ${ }^{1}$ \\ ${ }^{1}$ Faculty of Health Sciences, Uganda Martyrs University, Kampala, Uganda \\ Corresponding Author: Dr. Omona Kizito, Lecturer. E-mail: komona@umu.ac.ug, Tel: +256706464873
}

DOI: 10.47760/cognizance.2021.v01i03.005

\begin{abstract}
Background: Per 1000 live births, 336 mothers die from pregnancy-related causes in Uganda; most of which are preventable as 9,549 mothers' lives were saved from 2015-2020 through reaching the CIP $m C P R$ goal. Use of contraception can prevent unwanted pregnancies and unsafe abortions which could lead to loss of lives of the women involved. Studies elsewhere have shown that the contraceptive use among postnatal mothers has a strong association with unsafe abortions and deaths. Similarly, there is limited information regarding the factors associated with contraceptive use among postnatal mothers.

Objectives: The aim of this study was to determine the prevalence of contraceptive uptake and to establish individual, socio-economic and health facility related factors associated with contraceptive uptake among post-partum mothers, 15-49years of age in Kalisizo hospital, Kyotera district, central Uganda.

Materials and Methods: This was a hospital based cross sectional observational and analytic study. A total of 168 randomly selected participants were recruited to participate in the study. Univariate analysis, Bivariate and multivariate logistic regression were done using STATA version 14.0 to identify factors associated with postpartum uptake of contraceptives. Odds ratios with 95\% confidence interval were computed to determine the level of significance at bivariate whereas adjusted odds ratios were calculated at multivariate analysis to establish independent significant factors.

Results: The prevalence of uptake of contraceptives among postpartum women was $36.3 \%$. Age $(p=0.007)$ and area of residence $(p=0.025)$ remained significantly associated with the uptake of contraceptives among postpartum women. Support from partner to use contraceptives was found to be independently associated with the uptake of contraceptives among postpartum women $(p=0.024)$, with respondents who got support being 1.3times more likely to take up contraceptive (aOR=1.32, 95\% CI (0.02-0.76)). Higher educational level was more likely to increase chances of contraceptive uptake; primary level 1.6times, Ordinary level 1.8times, Advanced level 2.2times and Diploma level 5times respectively as opposed to mothers who never went to school. Feeling that health workers are few and overworked was associated with uptake of contraceptive $(p=0.001)$, with respondents who didn't feel that way being 2.5times more like to take up contraceptive (cOR=2.51, 95\% CI (1.25-5.02)).

Conclusion: The postpartum family planning uptake among women attending Kalisizo hospital is higher than national contraceptive prevalence rate. Interventions which are multi-pronged should be used to address multiple barriers to the uptake of postpartum family planning.

Keywords: Contraceptives, Contraceptive Prevalence Rate, Family planning, Postpartum Period, Reproductive Age
\end{abstract}




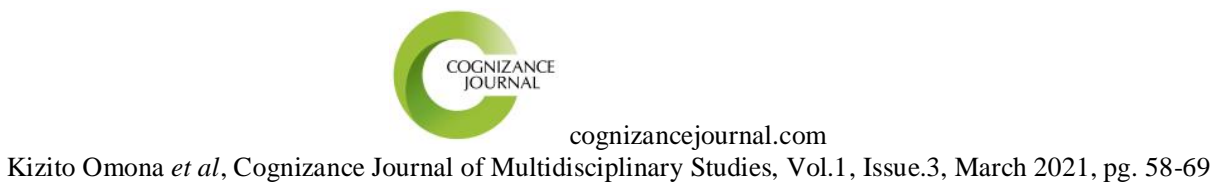

\section{INTRODUCTION}

\subsection{Background of the study}

Use of contraceptives can prevent unwanted pregnancies and unsafe abortions which could lead to loss of lives of the women involved. On the other hand, use of contraceptives allows individuals and couples to achieve their desired number through spacing and timing of their births (1). Enabling women to take part in their pregnancy preferences has turned into a high priority on the global development agenda. Strategies have called for a reduction on the unmet need for modern contraception, which comes about when women desire to avoid a pregnancy but are not utilizing any modern method or a traditional one (2).In countries with high birth rates, the promotion of family planning can prevent $32 \%$ of all maternal deaths and close to $10 \%$ of childhood deaths(3).

In Sub-Saharan Africa (SSA), unintended pregnancies are on the rise due to the low use of modern contraceptives which in turn lead to unsafe abortions and unplanned births with about two-thirds of women wanting to avoid pregnancy in their first year after delivery but are not on any postpartum contraceptive method with nearly $95 \%$ of them who are 0 to 12 months postpartum desiring to avoid pregnancy in the next 24 months while $70 \%$ of them resorting to not using contraception (4).

The coverage of contraceptives in eastern Africa stands at $40 \%$ and is expected to grow to55\% by 2030 (5). In Uganda, per 1000 live births, 336 mothers die from pregnancy-related causes most of which are preventable as 9,549 mothers' lives can be save from 2015-2020 through reaching the CIP mCPR goal and by method mix goals which is 963 more than if these family planning goals are not met (6). Over $90 \%$ and $40 \%$ of postpartum women in Uganda want to delay or avoid pregnancies for the next 1 and 2 years, respectively. Nevertheless, utilization of pre pregnancy family planning among remains low, with over $50 \%$ of women on modern contraception using condoms as the only method of family planning (7).

One of the main targets to reach the SDGs is to promote family planning and timely achievement of family planning targets is expected to hasten achievement across 5 SDG themes of People, Planet, Prosperity, Peace, and Partnership(8).In the postpartum period, the unmet need for FP remains excessively high and far surpasses the FP unmet need of other women whereby the birth-to-pregnancy intervals in 50\% or more of pregnancies in low and middle-income countries are too short at less than 23 months (9).Low FP uptake in Uganda, Kyotera inclusive has frequently resulted into high child and maternal mortality rates resulting from unsafe abortions (10). It affects mostly all post-natal mothers in 18 to 24 year age groups, those with lower levels of education and income (10).

Several interventions have been put in place by the Uganda $\mathrm{MOH}$ with support from WHO to increase uptake and accessibility to family planning information, targeting youth and addressing the social and cultural misconceptions about contraception and increase uptake of FP services (11). The extent to which the interventions implemented in Kyotera district to increase uptake of contraceptives in postpartum mothers has not been ascertained. Similarly, there is limited information regarding the factors affecting contraceptive use among postnatal mothers and it's completely non-existent in Kyotera district. The reason as to why some Ugandan women are not using family planning services is not clear especially among postpartum women. Therefore, this study sought to determine the prevalence of uptake of contraceptives and associated factors among postpartum mothers age $15-49$ years in Kalisizo hospital, Kyotera district in central Uganda and the study findings may influence the policy and practice on contraception uptake Uganda. 


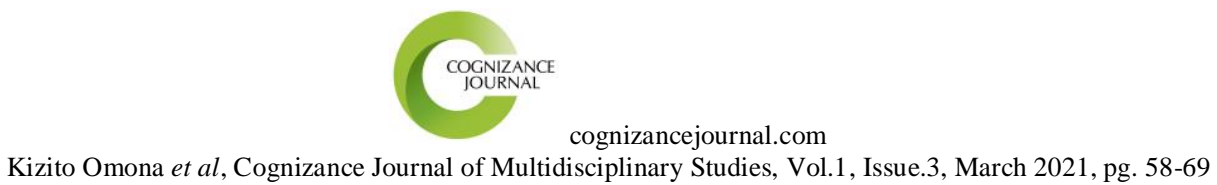

\subsection{Study Area}

The study was conducted in Kalisizo hospital. The hospital is located in kyotera district in Central Uganda about 30km South west of Masaka Regional Referral Hospital 29 kilometers southwest of Masaka and 61 kilometers north of Mutukula, the town at the international border with Tanzania. The health facility serves a catchment population of 518,008 people with a bed capacity of 120 beds and it is funded by the Government of Uganda and managed by the Ministry of Health $(\mathrm{MoH})$ through Kyotera District Local Government. The Hospital, besides serving the population in Kyotera Health Sub District (HSD), also performs as the referral Hospital for lower level health facilities in Kyotera, Rakai, Masaka and other surrounding districts. It has a catchment population of 73,100 people. This study was carried out in the clinical department with particular emphasis on the in-patients.

\subsection{Specific objectives}

(1) To determine the Prevalence of Contraceptive Uptake Among Postpartum Mothers aged 15-49years attending postnatal care in Kalisizo General hospital, Kyotera district

(2) To establish the individual factors associated with contraceptive uptake among postpartum mothers aged 15-49years attending postnatal care in Kalisizo General hospital, Kyotera district

(3) To ascertain the socio-economic factors associated with contraceptive uptake among postpartum mothers aged 15-49years attending postnatal care in Kalisizo General hospital, Kyotera district

(4) To examine the health facility factors associated with contraceptive uptake among postpartum mothers aged 15-49years attending postnatal care in Kalisizo General hospital, Kyotera district

\section{MATERIALS AND METHODS}

\subsection{Study design}

The study was a hospital based descriptive cross sectional and analytic study which predominantly quantitative. Cross sectional study design was chosen for the purpose of this study because it collects data from a relatively large population with the exposure and outcome being investigated at the same time and there is no need to follow up the participants.

\subsection{Study population}

Women of reproductive age 15-49years old living in Kyotera district and areas neighbouring Kalisizo hospital were targeted since majority of them could be receiving postnatal care from Kalisizo hospital.

\subsection{Inclusion and Exclusion Criteria}

\subsubsection{Inclusion criteria}

Women, aged 15-49years old attending postnatal care from Kalisizo hospital were included. Women 15-49years of age attending Postnatal Care in Kalisizo Family planning Clinic whose appointments dates fell within the period of data collection were included. 


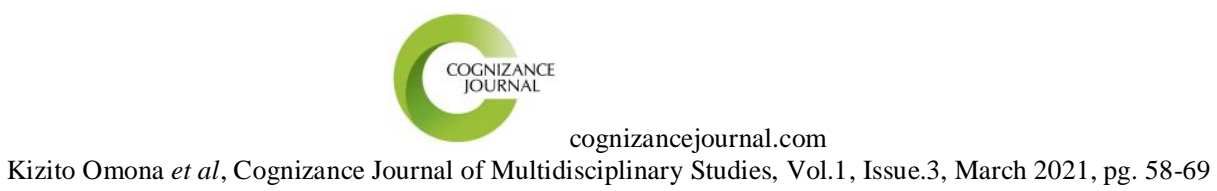

\subsubsection{Exclusion criteria}

Women aged less than 15years or older than 49years old attending health clinics in the health facility were excluded. Women 15-49years of age attending Postnatal Care in Kalisizo Family planning Clinic whose appointments dates fell outside the period of data collection were excluded.

\section{4 Sample size estimation}

Based on the number of mothers who attend postnatal care from the facility, the study recruited a total of 168 study participants. This was computed based on Taro Yamane formula;

$$
n=\frac{N}{\left(1+N e^{2}\right)}=168
$$

Where;

$$
\begin{aligned}
& \boldsymbol{n}=\text { the sample size } \\
& \mathrm{N}=\text { Population size } \\
& \mathrm{e}=\text { margin of error set at } 5 \%(0.05)
\end{aligned}
$$

\subsection{Sampling procedure}

The study adopted the Simple Random Sampling method on women of age 15-49years attending Postnatal Care at Kalisizo Hospital. The study unit was any postpartum woman found at the clinic during the study period who was receiving postnatal care from Kalisizo hospital and was aged between 15-49 years. The Researchers obtained the total number of 168 women by random technique. Women 15-49years of age attending Postnatal Care in Kalisizo Family planning Clinic whose appointments dates fell within the period of data collection were included.

\subsection{Data collection}

The researchers, together with research assistants, collected data using a pre-designed questionnaire. Research assistants were deployed to collect data from the postpartum women on every Monday since that is always the clinic day at the hospital. The oversight role was done by the researchers, as well as checking filled questionnaires for accuracy and any missing information. The questions in the questionnaires were closed ended questions with few open ended questions.

\subsection{Data Analysis}

For easy management, tools used in data collection were coded before data collection and afterward data was entered in the computer using Microsoft Excel. Cleaning and editing of the data was done before doing statistical analysis using STATA version 14.0. Both descriptive statistics and an inferential analysis were conducted on the collected data. Descriptive statistics were analyzed in terms of frequency and percentage. Categorical variables were compared using Chi-square test. Both bivariate and multivariate logistic regression was used to analyze data using a dichotomous dependent variable. This was used to describe data and explain the relationship between one or more categorical independent variables and the dependent variable and the level of significance was set at $p<0.05$. Odds ratio (OR) and 95\% Confidence Interval (CI) was calculated as a measurement of association between an independent variable and the outcome. Assumptions for use of multiple logistic regressions, such as the absence of multi-collinearity among the independent variables, were explored. 


\subsection{Ethical considerations}

The researchers obtained an approval from the research ethics committee at Uganda Martyrs University. Approval was also sought from the administration of the Kalisizo Hospital and in charges of the clinics where the study took place. The researchers informed all participants about the purpose of the study and a written informed consent was obtained before enrolment. A verbal consent was obtained for illiterate participants and they were asked to provide a fingerprint on the consent form. The study participants were reassured that their identities shall not be revealed.

\section{RESULTS}

\subsection{Socio-demographic Characteristics of Respondents}

Of the 168 postpartum women sampled, 67 (39.88\%) were in the age group of 21-25 years. The age of participants ranged from 16 to 36 years with a mean age of 24 years and a standard deviation of 5.12 from the mean. 143 (85.12\%) had given birth to 3 children, 251 $(65.36 \%)$ of the study participants were from monogamous families, 130 (77.38\%) had 2 children or less children living meanwhile. Majority $88(52.38 \%)$ of the participants were from urban areas with the highest proportion of the study participants 59 (35.12\%) being married. When asked type of marriage, majority of the study participants 120 (83.33\%) were in monogamous marriages with $93(66.91 \%)$ having been married for $1-4$ years.

Table 1: Socio-demographic characteristics of the study participants

\begin{tabular}{|c|c|c|c|}
\hline Variables & Categories & $\begin{array}{l}\text { Frequency } \\
\text { (n) }\end{array}$ & Percentage $(\%)$ \\
\hline \multirow[t]{4}{*}{ 1) Age in years } & - $16-20$ Years & 51 & 30.36 \\
\hline & - $21-25$ Years & 67 & 39.88 \\
\hline & - $26-30$ Years & 28 & 16.67 \\
\hline & - 31Years or more & 22 & 13.10 \\
\hline \multirow{2}{*}{$\begin{array}{l}\text { 2) Number of children ever } \\
\text { born }\end{array}$} & - $\leq 3$ Children & 143 & 85.12 \\
\hline & - $>3$ Children & 25 & 14.88 \\
\hline \multirow[t]{2}{*}{ 3) Number of children living } & - $\leq 2$ Children & 130 & 77.38 \\
\hline & - $>2$ Children & 38 & 22.62 \\
\hline \multirow[t]{2}{*}{ 4) Area of Residence } & - Urban & 88 & 52.38 \\
\hline & - Rural & 80 & 47.62 \\
\hline \multirow{4}{*}{ 5) Marital status } & - Never Married & 28 & 16.67 \\
\hline & - Married & 59 & 35.12 \\
\hline & - Divorced & 05 & 02.98 \\
\hline & - Co-habiting & 76 & 45.24 \\
\hline \multirow[t]{2}{*}{ 6) Type of Marriage } & - Monogamy & 120 & 83.33 \\
\hline & - Polygamy & 24 & 16.67 \\
\hline \multirow[t]{3}{*}{ 7) Number of years Married } & - 1-4Years & 93 & 66.91 \\
\hline & - 5 - 8Years & 25 & 17.99 \\
\hline & - 9Years \& above & 21 & 15.11 \\
\hline
\end{tabular}




\subsection{Prevalence of Contraceptive Uptake Among Postpartum Mothers}

The prevalence of contraceptive uptake among postpartum women attending Kalisizo hospital was $36.3 \%$. The age group with the highest uptake of contraceptives was 16-20 years with a prevalence of $52.9 \%$

\subsection{Individual Factors Associated With Contraceptive Uptake Among Postpartum Mothers}

Both Bivariate and multivariate analysis was run and the results are shown in table 2 below.

\section{Table 2: Logistic Regression Showing Association Between Individual Factors and Contraceptive Uptake}

\begin{tabular}{|c|c|c|c|c|c|c|}
\hline \multirow[t]{2}{*}{ Variables } & \multicolumn{2}{|c|}{ Contraceptive Uptake } & \multirow{2}{*}{$\begin{array}{l}\text { cOR } \\
(95 \% \mathrm{CI})\end{array}$} & \multirow[t]{2}{*}{ P Value } & \multirow{2}{*}{$\begin{array}{l}\text { aOR } \\
(95 \% \mathrm{CI})\end{array}$} & \multirow{2}{*}{$\begin{array}{l}\text { P- } \\
\text { Value }\end{array}$} \\
\hline & No & Yes & & & & \\
\hline \multicolumn{7}{|l|}{ Age of the women } \\
\hline - 16-20Years & $24(47.1 \%)$ & $27(52.9 \%)$ & 1 & - & 1 & - \\
\hline - $21-25$ Years & $48(71.6 \%)$ & $19(28.4 \%)$ & $0.35(0.16-0.76)$ & $0.007 *$ & $0.19(0.05-0.81)$ & $0.025 *$ \\
\hline - $26-30$ Years & $19(67.9 \%)$ & $09(32.1 \%)$ & $0.42(0.16-1.11)$ & 0.079 & $0.01(0.001-0.15)$ & $<0.001^{*}$ \\
\hline - 31Years/ more & $16(72.7 \%)$ & $06(27.3 \%)$ & $0.33(0.11-0.99)$ & $0.048 *$ & $0.21(0.03-1.57)$ & 0.127 \\
\hline \multicolumn{7}{|c|}{ Number of children born } \\
\hline - $\leq 3$ Children & $94(65.7 \%)$ & $49(34.3 \%)$ & 1 & - & - & - \\
\hline - $\quad>3$ Children & $13(52.0 \%)$ & $12(48.0 \%)$ & $1.77(0.75-4.17)$ & 0.191 & - & - \\
\hline \multicolumn{7}{|c|}{ Number of children living } \\
\hline - $\leq 2$ Children & $81(62.3 \%)$ & $49(37.7 \%)$ & 1 & - & - & - \\
\hline - $>2$ Children & $26(68.4 \%)$ & $12(31.6 \%)$ & $0.76(0.35-1.65)$ & 0.491 & & \\
\hline \multicolumn{7}{|l|}{ Area of residence } \\
\hline - Urban & $49(55.7 \%)$ & $39(44.3 \%)$ & 1 & - & 1 & - \\
\hline - $\quad$ Rural & $58(72.5 \%)$ & $22(27.5 \%)$ & $0.48(0.25-0.91)$ & $0.025 *$ & $0.28(0.08-0.95)$ & $0.041 *$ \\
\hline \multicolumn{7}{|l|}{ Marital status } \\
\hline - $\quad$ Never Married & $12(42.9 \%)$ & $16(57.1 \%)$ & 1 & - & - & - \\
\hline - $\quad$ Married & $42(71.2 \%)$ & $17(28.8 \%)$ & $0.30(0.19-0.77)$ & $0.013 *$ & - & - \\
\hline - $\quad$ Divorced & $05(100.0 \%)$ & $00(0.0 \%)$ & 1 (omitted) & & - & - \\
\hline - $\quad$ Co-habiting & $48(63.2 \%)$ & $28(36.8 \%)$ & $0.44(0.18-1.06)$ & 0.066 & - & - \\
\hline \multicolumn{7}{|l|}{ Type of Marriage } \\
\hline - Monogamy & $80(66.7 \%)$ & $40(33.3 \%)$ & 1 & - & - & - \\
\hline - $\quad$ Polygamy & $19(79.2 \%)$ & $05(20.8 \%)$ & $0.52(0.18-1.51)$ & 0.233 & - & - \\
\hline \multicolumn{7}{|c|}{ Number of years Married } \\
\hline - $\quad 1-4$ Years & $70(75.3 \%)$ & $23(24.7 \%)$ & 1 & - & - & - \\
\hline - 5 - 8 Years & $20(80.0 \%)$ & $05(20.0 \%)$ & $0.76(0.26-2.26)$ & 0.622 & - & - \\
\hline - $\quad 9$ Years /more & $09(42.9 \%)$ & $12(57.1 \%)$ & $4.06(1.52-10.86)$ & 0.005 & - & - \\
\hline
\end{tabular}

$\boldsymbol{c O R}=$ Crude Odds Ratio, aOR=Adjusted Odds Ratio, $\boldsymbol{C I}=$ Confidence Interval 
At multivariate logistic regression analysis, age $(\mathrm{p}=0.007)$ and area of residence $(\mathrm{p}=0.025)$ remained significantly associated with the uptake of contraceptives among postpartum women. Participants who were in the age group of 21-25years were 0.35 times less likely to use contraception than those in the age group of 16-20years (aOR 0.19, 95\% CI (0.05-0.81), $\mathrm{p}=0.025)$, meanwhile age group of 26-30years was associated with uptake of contraceptive $(\mathrm{p}=0.001)$. On the other hand, area of residence was associated with contraceptive uptake $(\mathrm{p}=0.041)$, with participants who were from rural areas of residence were 0.28times less likely to use contraception as compared to participants who were coming from urban areas (aOR 0.28, 95\% CI (0.08-0.95), $\mathrm{p}=0.041)$.

\subsection{Socio-economic Factors Associated With Contraceptive Uptake Among Postpartum}

\section{Mothers}

Both Bivariate and multivariate analysis was run and the results are shown in table 3 below.

\section{Table 3: Logistic Regression Showing Association between Socio-economic Factors and Contraceptive Uptake among Postpartum Mothers}

\begin{tabular}{|c|c|c|c|c|c|c|}
\hline \multirow[t]{2}{*}{ Variables } & \multicolumn{2}{|c|}{ Contraceptive Uptake } & \multirow[t]{2}{*}{$\operatorname{cOR}(95 \%$ CI $)$} & \multirow[t]{2}{*}{ P Value } & \multirow[t]{2}{*}{ aOR (95\% CI) } & \multirow[t]{2}{*}{ P Value } \\
\hline & No & Yes & & & & \\
\hline \multicolumn{7}{|l|}{ Education Level } \\
\hline - $\quad$ Never Educated & $18(75.0 \%)$ & $06(25.0 \%)$ & 1 & - & - & - \\
\hline - $\quad$ Primary & $42(64.6 \%)$ & $23(35.4 \%)$ & $1.64(0.57-4.72)$ & 0.356 & - & - \\
\hline - “O” Level & $40(62.5 \%)$ & $24(37.5 \%)$ & $1.8(0.63-5.16)$ & 0.274 & - & - \\
\hline - “A" Level & $04(57.1 \%)$ & $03(42.9 \%)$ & $2.25(0.39-13.07)$ & 0.366 & - & - \\
\hline - $\quad$ Diploma & $03(37.5 \%)$ & $05(62.5 \%)$ & $4.99(0.91-27.47)$ & 0.064 & - & - \\
\hline \multicolumn{7}{|l|}{ Occupation } \\
\hline - $\quad$ Farmer & $31(70.5 \%)$ & $13(29.5 \%)$ & 1 & - & - & - \\
\hline - $\quad$ Business & $20(58.8 \%)$ & $14(41.2 \%)$ & $1.67(0.65-4.28)$ & 0.286 & - & - \\
\hline - $\quad$ Civil Servant & $11(55.0 \%)$ & $09(45.0 \%)$ & $1.95(0.65-5.82)$ & 0.231 & - & - \\
\hline - $\quad$ Private employee & $02(50.0 \%)$ & $02(50.0 \%)$ & $2.38(0.30-18.80)$ & 0.409 & - & - \\
\hline - $\quad$ Self employed & $19(55.9 \%)$ & $15(44.1 \%)$ & $1.88(0.74-4.80)$ & 0.186 & - & - \\
\hline - $\quad$ Others & $24(75.0 \%)$ & $08(25.0 \%)$ & $0.79(0.28-2.23)$ & 0.662 & - & - \\
\hline \multicolumn{7}{|l|}{ Religion } \\
\hline - $\quad$ Catholic & $61(71.8 \%)$ & $24(28.2 \%)$ & 1 & - & - & - \\
\hline - $\quad$ Anglican & $30(65.2 \%)$ & $16(34.8 \%)$ & $1.36(0.63-2.92)$ & 0.438 & - & - \\
\hline - Jehova witness & $02(20.0 \%)$ & $08(80.0 \%)$ & $10.17(2.01-51.4)$ & $0.005 *$ & - & - \\
\hline - $\quad$ Muslim & $03(37.5 \%)$ & $05(62.5 \%)$ & $4.23(0.94-19.12)$ & 0.060 & - & - \\
\hline - $\quad$ No religion & $11(57.9 \%)$ & $08(42.1 \%)$ & $1.85(0.66-5.16)$ & 0.240 & - & - \\
\hline \multicolumn{7}{|c|}{ Discussion about Family Planning with Partner } \\
\hline - Yes & $54(58.1 \%)$ & $39(41.9 \%)$ & 1 & - & 1 & - \\
\hline - No & $45(75.0 \%)$ & $15(25.0 \%)$ & $0.46(0.23-0.94)$ & $0.034 *$ & $0.29(0.17-2.97)$ & 0.258 \\
\hline \multicolumn{7}{|c|}{ Support from Partner to use Contraceptives } \\
\hline - No & $47(56.6 \%)$ & $36(43.4 \%)$ & 1 & - & - & - \\
\hline - Yes & $38(86.4 \%)$ & $06(13.6 \%)$ & $0.21(0.08-0.54)$ & $0.001 *$ & $1.32(0.02-0.76)$ & $0.024 *$ \\
\hline \multicolumn{7}{|c|}{ Partner and woman's desire for Children } \\
\hline - $\quad$ All want the same & $62(71.3 \%)$ & $25(28.7 \%)$ & 1 & - & - & - \\
\hline $\begin{array}{ll}\text { - } & \begin{array}{l}\text { Husband wants } \\
\text { more }\end{array} \\
\end{array}$ & $28(63.6 \%)$ & $16(36.4 \%)$ & $1.42(0.66-3.06)$ & 0.375 & - & - \\
\hline $\begin{array}{ll}\text { Husband wants } \\
\text { less }\end{array}$ & $04(66.7 \%)$ & $02(33.3 \%)$ & $1.24(0.21-7.21)$ & 0.811 & - & - \\
\hline \multicolumn{7}{|c|}{ Family planning methods are effective } \\
\hline - Yes & $59(57.8 \%)$ & $43(42.2 \%)$ & 1 & - & 1 & - \\
\hline - $\quad \mathrm{No}$ & $06(37.5 \%)$ & $10(62.5 \%)$ & $2.29(077-6.78)$ & 0.135 & $3.69(0.62-22.02)$ & 0.151 \\
\hline
\end{tabular}




\begin{tabular}{|c|c|c|c|c|c|c|}
\hline - Don’t Know & $42(84.0 \%)$ & $08(16.0 \%)$ & $0.26(0.11-0.61)$ & $0.002 *$ & $3.15(0.39-24.99)$ & 0.278 \\
\hline \multicolumn{7}{|c|}{ Family's Average household monthly income } \\
\hline - $\quad<500,000$ & $82(78.1 \%)$ & $23(21.9 \%)$ & 1 & - & - & - \\
\hline $\begin{array}{ll}\text { - } & 500,000- \\
& 1,000,000\end{array}$ & $21(41.2 \%)$ & $30(58.8 \%)$ & $2.09(2.47-10.51)$ & $<0.001 *$ & - & - \\
\hline - $\quad 1.1$ Million-1.5 M & $04(33.3 \%)$ & $08(66.7 \%)$ & $7.13(1.97-25.81)$ & $0.003 *$ & - & - \\
\hline \multicolumn{7}{|c|}{ Asked to pay for contraceptive services } \\
\hline - Yes & $20(42.6 \%)$ & $27(57.4 \%)$ & 1 & - & - & - \\
\hline - $\quad$ No & $87(71.9 \%)$ & $34(28.1 \%)$ & $0.29(0.14-0.58)$ & $0.001 *$ & - & - \\
\hline
\end{tabular}

$\boldsymbol{c O R}=$ Crude Odds Ratio, $\boldsymbol{a O R}=$ Adjusted Odds Ratio, $\boldsymbol{C I}=$ Confidence Interval

Support from partner to use contraceptives was found to be independently associated with the uptake of contraceptives among postpartum women $(\mathrm{p}=0.024)$, with respondents who got support being 1.3times more likely to take up contraceptive $(\mathrm{aOR}=1.32,95 \% \mathrm{CI}(0.02-0.76))$. Higher educational level was more likely to increase chances of contraceptive uptake; primary level 1.6times, Ordinary level 1.8times, Advanced level 2.2times and Diploma level 5times respectively as opposed to mothers who never went to school.

\subsection{Health Facility Factors Associated with Contraceptive Uptake Among Postpartum Mothers}

Both bivariate and multivariate analysis was run. See table 4 below for the results

Table 4: Logistic Regression Showing Association between Health Facility Related Factors and Contraceptive Uptake Among Postpartum Mothers

\begin{tabular}{|c|c|c|c|c|c|c|}
\hline \multirow[t]{2}{*}{ Variables } & \multicolumn{2}{|c|}{ Contraceptive Uptake } & \multirow{2}{*}{$\begin{array}{l}\text { cOR } \\
(95 \% \mathrm{CI})\end{array}$} & \multirow[t]{2}{*}{ P Value } & \multirow{2}{*}{$\begin{array}{l}\mathrm{aOR} \\
(95 \% \mathrm{CI})\end{array}$} & \multirow{2}{*}{$\begin{array}{l}\mathbf{P} \\
\text { Value }\end{array}$} \\
\hline & No & Yes & & & & \\
\hline \multicolumn{7}{|c|}{ Awareness of Other facilities where FP is offered } \\
\hline - Yes & $46(49.5 \%)$ & $47(50.5 \%)$ & 1 & - & 1 & - \\
\hline - No & $61(81.3 \%)$ & $14(18.7 \%)$ & $0.22(0.11-0.46)$ & $<0.001 *$ & $0.63(0.16-2.52)$ & 0.512 \\
\hline \multicolumn{7}{|c|}{ Distance Between home and hospital } \\
\hline - $\quad 1-2 \mathrm{~km}$ & $50(66.7 \%)$ & $25(33.3 \%)$ & 1 & - & - & - \\
\hline - $\quad 3-4 \mathrm{~km}$ & $39(56.5 \%)$ & $30(43.5 \%)$ & $1.53(0.78-3.02)$ & 0.212 & - & - \\
\hline - $\quad \geq 5 \mathrm{~km}$ & $18(75.0 \%)$ & $06(25.0 \%)$ & $0.67(0.24-1.89)$ & 0.445 & - & - \\
\hline \multicolumn{7}{|c|}{ Ever Visited Hospital But Missed Family planning services } \\
\hline - Yes & $13(50.0 \%)$ & $13(50.0 \%)$ & 1 & - & - & - \\
\hline - No & $94(66.2 \%)$ & $48(33.8 \%)$ & $0.51(0.22-1.19)$ & 0.118 & - & - \\
\hline \multicolumn{7}{|c|}{ Hospitality of service providers } \\
\hline - Hospitable & $24(33.8 \%)$ & $47(66.2 \%)$ & 1 & - & 1 & - \\
\hline - $\quad$ Moderate & $02(15.4 \%)$ & $11(84.6 \%)$ & $2.81(0.58-13.7)$ & 0.202 & $0.29(0.17-2.97)$ & 0.258 \\
\hline - Harsh & $04(57.1 \%)$ & $03(42.9 \%)$ & $0.33(0.08-1.85)$ & 0.233 & & \\
\hline \multicolumn{7}{|c|}{ Perception of health workers being qualified } \\
\hline - Yes & $80(58.0 \%)$ & $58(42.0 \%)$ & 1 & - & - & - \\
\hline - $\quad$ No & $27(90.0 \%)$ & $03(10.0 \%)$ & $0.15(0.04-0.53)$ & $0.003 *$ & - & - \\
\hline \multicolumn{7}{|c|}{ Availability of Family planning services } \\
\hline - Yes & $66(61.7 \%)$ & $41(38.3 \%)$ & 1 & - & - & - \\
\hline - No & $37(77.1 \%)$ & $11(22.9 \%)$ & $0.48(0.22-1.04)$ & 0.063 & $0.12(0.01-1.64)$ & 0.111 \\
\hline - Don't know & $04(30.8 \%)$ & $09(69.2 \%)$ & $3.62(1.05-12.5)$ & $0.042 *$ & $2.19(0.42-11.49)$ & 0.354 \\
\hline \multicolumn{7}{|c|}{ Satisfaction with services offered at the facility } \\
\hline - Yes & $91(63.6 \%)$ & $52(36.4 \%)$ & 1 & - & - & - \\
\hline - No & $16(64.0 \%)$ & $09(36.0 \%)$ & $0.98(0.41-2.38)$ & 0.972 & - & - \\
\hline \multicolumn{7}{|c|}{ Few and overworked health workers } \\
\hline - Yes & $85(69.7 \%)$ & $37(30.3 \%)$ & 1 & - & 1 & - \\
\hline - No & $22(47.8 \%)$ & $24(52.2 \%)$ & $2.51(1.25-5.02)$ & $0.010 *$ & $22.82(3.32-156.6)$ & $0.001 *$ \\
\hline \multicolumn{7}{|c|}{ Ever been counseled about family planning by health worker } \\
\hline - Yes & $64(53.3 \%)$ & $56(46.7 \%)$ & 1 & - & 1 & - \\
\hline - $\quad \mathrm{No}$ & $43(89.6 \%)$ & $05(10.4 \%)$ & $0.13(0.05-0.36)$ & $<0.001 *$ & $0.11(0.01-1.55)$ & 0.102 \\
\hline
\end{tabular}


cognizancejournal.com

Kizito Omona et al, Cognizance Journal of Multidisciplinary Studies, Vol.1, Issue.3, March 2021, pg. 58-69

\begin{tabular}{|c|c|c|c|c|c|c|}
\hline \multicolumn{7}{|c|}{ Convenience in the schedule of FP clinic } \\
\hline - Yes & $56(60.2 \%)$ & $37(39.8 \%)$ & 1 & - & - & - \\
\hline - $\quad$ No & $51(68.0 \%)$ & $24(32.0 \%)$ & $0.71(0.38-1.35)$ & 0.298 & - & - \\
\hline \multicolumn{7}{|c|}{ Adequate working environment at FP clinic } \\
\hline - Yes & $95(66.9 \%)$ & $47(33.1 \%)$ & 1 & - & 1 & - \\
\hline - $\quad$ No & $12(46.2 \%)$ & $14(53.8 \%)$ & $2.36(1.01-5.50)$ & $0.047 *$ & $2.07(0.32-13.28)$ & $0.441)$ \\
\hline \multicolumn{7}{|c|}{ Failure to access a specific type of contraceptive } \\
\hline - Yes & $10(41.7 \%)$ & $14(58.3 \%)$ & 1 & & 1 & - \\
\hline - $\quad$ No & $97(67.4 \%)$ & $47(32.6 \%)$ & $0.35(0.14-0.84)$ & $0.019 *$ & $0.16(0.02-1.63)$ & 0.122 \\
\hline
\end{tabular}

$\boldsymbol{c O R}=$ Crude Odds Ratio, $\boldsymbol{a O R}=$ Adjusted Odds Ratio, $\boldsymbol{C I}=$ Confidence Interval

Feeling that health workers are few and overworked was associated with uptake of contraceptive $(\mathrm{p}=0.001)$, with respondents who didn't feel that way being 2.5 times more like to take up contraceptive $(\mathrm{cOR}=2.51,95 \% \mathrm{CI}(1.25-5.02))$. Adequate working environment at FP clinic was found to be associated with contraceptive uptake $(\mathrm{p}=0.047)$. Having ever been counseled about family planning by health worker $(\mathrm{p}=0.001)$, perception that health workers are qualified $(\mathrm{p}=0.003)$ and being aware of other health facilities where family planning is available $(\mathrm{p}=0.001)$ were found to be associated with contraceptive uptake respectively.

\section{DISCUSSIONS}

In this study, less than a quarter $(36.31 \%)$ of the study participants reported the use of contraceptives during the postpartum period. This finding in agreement with studies conducted in Nigeria (35.1\%)(12), Juba city of Sudan (36\%)(13). The agreement in the study findings could be attributed to the similarity in methodologies adopted in the highlighted studies and the similarity in the study settings. This finding of the present study is higher than the prevalence found in studies done among postpartum mothers in Uganda $(28 \%)(14)$ and in Ethiopia (12.3\%)(15). This difference in the findings could be attributed to the health education strategy through media being employed by the Ugandan ministry of health and the strategy of increasing access to sexual and reproductive health services conducting outreaches through extension health workers.

The prevalence of postpartum contraceptive uptake found in this study is low compared with the $86.3 \%$ found in Kenya (16), 74.6\% in Malawi (17), $48.4 \%$ in town of Gondar (18). This difference in study findings may be due to the study setting as the present study was conducted in a government general hospital and there is a possibility that other postpartum women could be attending to other hospitals or perhaps private health facilities.

In this study, the use of long acting contraceptives such that intrauterine contraceptive device was high among the study participants. This finding is in in disagreement with studies which specify that majority women who embrace modern contraceptive methods in the postpartum period most likely to choose short term hormonal methods (19). Findings of this study revealed that minority $04(06.06 \%)$ of the study participants were users of injectable DepoProvera. This finding is opposed to the results of a study which showed that the majority of current contraceptive users were injectables 26 (38.8\%) (15).

The study findings propose that a higher frequency of women in the age group of 21-25 years and 26-30 years were less likely to adopt postpartum family planning as opposed to their counterparts who are in the younger age group of 16-20 years. This is in line with a study done in America (20). The reason for more utilization of contraception among the younger age group could be before majority of those are still unmarried and do not want to carry the burden of bearing many children for a man whom they are not sure they will get married to. Contrary to what was found in this study, there is a body of knowledge which states that the lowest use of contraceptive is observed among young women, rises to a peak among women in their thirties and faces a decline among older women (21). 


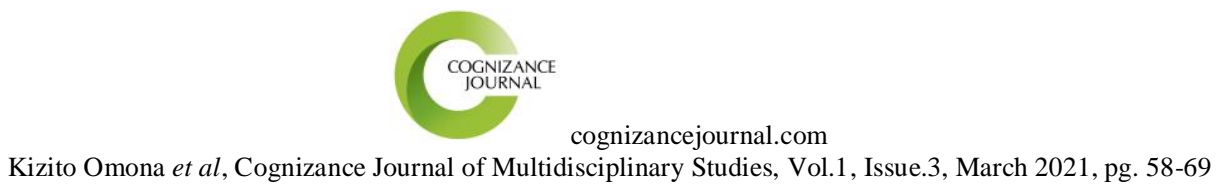

This study established that coming from rural areas of residence was associated with less likelihood to use contraception. This finding is in line with the results of a studies done in south Sudan (22), Nigeria (23), Bangladesh (24), Ghana (25). This could be explained by the fact that to a larger extent the area of residence of an individual can influence the kind of work an individual will possibly do to earn a living with rural dwellers engaging in activities that may not give them adequate time to go and receive family planning services and also, there is service deliver gap in that rural areas have few facilities which in most cases are illequipped to offer sexual and reproductive health services to the potential seekers.

Contrary to the findings of this study, a study in Ghana revealed that many urban women avoided hormonal methods (26). The possible reason could be because urban women are enlightened and are aware about the side effects and health risks linked to some of the contraceptive methods. A population level analysis of a study done in Uganda showed no independent association between area of residence of the women and their likelihood to use contraceptives unlike what was found in the present study (27). The variation in the findings could be due to the different study settings whereby the previous study was a nationally population survey whereas the present study is a facility based cross sectional study conducted in only one hospital. This study found that support from partner to use contraceptives was independently significantly associated with the uptake of contraceptives among postpartum women. This finding is supported by the results of studies conducted in Ethiopia (28), and (21). When a woman receives support from her partner, she will be confident while embracing contraceptive use knowing that no family violence will arise from her use of contraceptives due to conflict of interest whereby a man may be in need of a child. Having few and overworked health workers was found to be independently associated with the uptake of contraceptives among postpartum women. This is in line with results of studies done Kenya (29), Burundi (30). When health workers are few and over worked, there is a high tendency that they will become harsh and rude to the clients due to psychological stress which will in turn make the women to shun contraceptives as evident in a study conducted in Nigeria which revealed that unwelcoming attitude of health workers was one of the factors identified as militating against the utilization of family planning methods (2). Also, being overworked may make the health workers to deliver shoddy services to the clients which may result into ineffectiveness of the contraceptives thereby leading to a perception among the clients that the health workers are not qualified. This may lead to a drop in the utilization of family planning services among women of reproductive age (31). A recent study in Uganda among postpartum mothers in Butambala district (32) found similar results with this current study.

\section{CONCLUSION}

The postpartum family planning uptake among women attending Kalisizo hospital is higher than national contraceptive prevalence rate. Women's ages, areas of residence, support from partner and few health workers at the facility were the key predictors of postpartum family planning uptake among women in Kyotera district attending Kalisizo hospital. From the results of this study, it appeared that the respondents didn't have the desire to bear children until during the later years in life as it can be inferred from the remarkable drop in the use of contraception among the study participants. In resource-limited settings where there is scarce access to information, uptake of postpartum family planning will not be ensured by accessibility of modern family planning methods alone particularly when access is narrowed to clinical settings. Interventions which are multi-pronged should be used to address multiple barriers to the uptake of postpartum family planning simultaneously. 


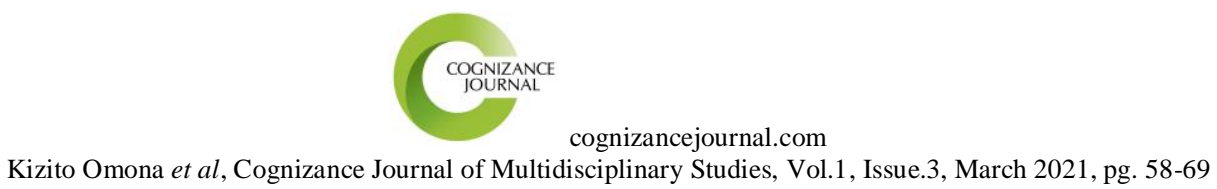

\section{ACKNOWLEDGEMENTS}

The authors would like to thank the mothers who participated in the study and we acknowledge the contribution of Kalisizo General Hospital and lastly the Staff at Uganda Martyrs University, Faculty of Health Sciences.

\section{DECLARATION}

The authors declare that they had no conflict of interest.

\section{REFERENCES}

[1]. Apanga PA, Adam MA. Factors influencing the uptake of family planning services in the Talensi District, Ghana. 2015;8688:1-9.

[2]. Agunbiade FBR. Factors Affecting the Utilization of Family Planning among Women Attending Selected Health Centers in Ile Ife, Osun State, Nigeria. Texila Int J Nurs Vol. 2017;3(2):1-8.

[3]. Gebremedhin AY, Kebede Y, Gelagay AA, Habitu YA. Family planning use and its associated factors among women in the extended postpartum period in Addis Ababa, Ethiopia. Contracept Reprod Med. 2018;3(1):1.

[4]. Coomson JI, Manu A. Determinants of modern contraceptive use among postpartum women in two health facilities in urban Ghana: a cross-sectional study. Contracept Reprod Med. 2019;4(1):17.

[5]. United Nations. Trends in Contraceptive Use Worldwide. Obtenido Dep Econ Soc Aff. 2015;

[6]. UNFPA. familyPlanning: the right investment to drive Uganda's socio-economic transformation. 2017;

[7]. Atukunda EC, Mugyenyi GR, Obua C, Atuhumuza EB, Lukyamuzi EJ, Kaida A, et al. Provision of family planning vouchers and early initiation of postpartum contraceptive use among women living with HIV in southwestern Uganda: A randomized controlled trial. PLoS Med. 2019;16(6).

[8]. United Nations. Repoductive Rights. Department of Economics and Social Affairs. 2020.

[9]. Tran NT, Gaffield ME, Seuc A, Landoulsi S, Yamaego WME, Cuzin-Kihl A, et al. Effectiveness of a package of postpartum family planning interventions on the uptake of contraceptive methods until twelve months postpartum in Burkina Faso and the Democratic Republic of Congo: the YAM DAABO study protocol. BMC Health Serv Res. 2018;18(1):112.

[10].Munakampe MN, Zulu JM, Michelo C. Contraception and abortion knowledge, attitudes and practices among adolescents from low and middle-income countries: a systematic review. BMC Health Serv Res. 2018;5:1-13.

[11].Nuwasiima A, Nuwamanya E, Babigumira JU, Nalwanga R, Asiimwe FT, Babigumira JB. Acceptability and utilization of family planning benefits cards by youth in slums in Kampala, Uganda. Contracept Reprod Med. 2019;4(1):10.

[12].Duru CB, Emelumadu OF, Iwu AC, Ohanle I, Agunwa CC, Nwaigbo E, et al. SocioDemographic Determinants of Family Planning Service Utilization among Women of Reproductive Age in Urban Communities of Imo State, Nigeria. 2018;5:1-21.

[13]. Obwoya JG, Wulifan JK, Kalolo A. Factors Influencing Contraceptives Use among Women in the Juba City of South Sudan. 2018;2018.

[14].Rutaremwa G, Kabagenyi A, Wandera SO, Jhamba T, Akiror E, Nviiri HL. Predictors of modern contraceptive use during the postpartum period among women in Uganda: a population-based cross sectional study. BMC Public Health. 2015;15(1):262.

[15].Nigussie A, Girma D, Tura G. Postpartum Family Planning Utilization and Associated Factors among Women who Gave Birth in the Past 12 Months, Kebribeyah Town, Somali Region, Journal of Women 's Health Care. 2016;5(6). 
cognizancejournal.com

Kizito Omona et al, Cognizance Journal of Multidisciplinary Studies, Vol.1, Issue.3, March 2021, pg. 58-69

[16].Jalang'O R, Thuita F, Barasa SO, Njoroge P. Determinants of contraceptive use among postpartum women in a county hospital in rural Kenya. BMC Public Health. 2017;17(1):1-8.

[17].Bwazi C, Maluwa A, Chimwaza A, Pindani M. Utilization of postpartum family planning services between six and twelve months of delivery at Ntchisi District Hospital, Malawi. Health (Irvine Calif). 2014;2014.

[18]. Abera Y, Mengesha ZB, Tessema GA. Postpartum contraceptive use in Gondar town, Northwest Ethiopia: a community based cross-sectional study. BMC Womens Health. 2015;15(1):19.

[19].Gebreselassie T, Shea OR, Vinod M. Contraceptive Use, Breastfeeding, Amenorrhea and Abstinence During the Postpartum Period: An Analysis of Four Countries. DHS Anal Stud No 14 Calverton, Maryland, USA Macro Int Inc. 2008;

[20].Dahlke JD, Ramseyer AM, Terpstra ER, Doherty DA, Keeler SM, Magann EF. Postpartum use of long-acting reversible contraception in a military treatment facility. J Women's Heal. 2012;21(4):388-92.

[21].Palamuleni ME. Socio-Economic and Demographic Factors Affecting Contraceptive use in Malawi. Afr J Reprod Health. 2013;17(September):91-104.

[22].Amen W, Ahmed M, Shokai SB, Abduelkhair IH. Factors Affecting Utilization of Family Planning Services in a Post-Conflict Setting, South Sudan: A Qualitative Study. 2015;2(May):655-66.

[23].Salami IC. Socio-Demographic Factors, Contraceptive Use and Fertility Preference among Married Women in South- South Region of Nigeria. 2016;504-10.

[24].Hossain MB, Khan MHR, Ababneh F, Shaw JEH. Identifying factors influencing contraceptive use in Bangladesh: evidence from BDHS 2014 data. BMC Public Health. 2018;18(1):1-14.

[25]. Teye JK. Modern contraceptive use among women in the Asuogyaman district of Ghana: is reliability more important than health concerns? Afr J Reprod Health. 2013;17(2):58-71.

[26]. Machiyama K, Cleland J. Unmet need for family planning in Ghana: the shifting contributions of lack of access and attitudinal resistance. Stud Fam Plann. 2014;45(2):203-26.

[27]. Namasivayam A, Lovell S, Namutamba S, Schluter PJ. Predictors of modern contraceptive use among women and men in Uganda : a population- - level analysis. 2020;1-11.

[28]. Mekonnen W, Worku A. Determinants of low family planning use and high unmet need in Butajira District, South Central Ethiopia. Reprod Health. 2011;8(1):37.

[29]. Ontiri S, Ndirangu G, Kabue M, Biesma R, Stekelenburg J. Long-Acting Reversible Contraception Uptake and Associated Factors among Women of Reproductive Age in Rural Kenya. Int J Environ Res Public Health. 2019;16:1-11.

[30]. Ndayizigiye M, Fawzi MCS, Lively CT, Ware NC. Understanding low uptake of contraceptives in resource-limited settings: a mixed-methods study in rural Burundi. BMC Health Serv Res. 2017;17(1):1-12.

[31].Ackerson K, Zielinski R. Factors in fl uencing use of family planning in women living in crisis a ff ected areas of Sub-Saharan Africa: A review of the literature. 2017;54(January):35-60.

[32]. Omona $\mathrm{K} \&$ Namuli $\mathrm{W}$. Factors influencing utilization of intra-uterine device among postpartum mothers at Gombe Hospital, Butambala district, Uganda Cogent Medicine 7(1). DOI: https://doi.org/10.1080/2331205X.2020.1846264 